\title{
O Enfrentamento dos Acadêmicos de Medicina da Universidade Severino Sombra Frente ao Processo Morte-Morrer
}

\author{
João Carlos de Souza Côrtes Jr \\ Universidade Severino Sombra, Centro de Ciências da Saúde, \\ Docente do Curso de Medicina \\ joaocortes@yahoo.com.br \\ Diego Santa Rosa \\ Universidade Severino Sombra, Centro de Ciências da Saúde, \\ Discente do Curso de Medicina \\ diegosr.med@hotmail.com \\ Tiago Souza Lopes \\ Universidade Severino Sombra, Centro de Ciências da Saúde, \\ Discente do Curso de Medicina \\ tiagoiguatu@hotmail.com \\ Paula Pitta de Resende Côrtes \\ Universidade Severino Sombra, Centro de Ciências da Saúde, \\ Docente do Curso de Medicina \\ paulapitta@yahoo.com.br
}

\begin{abstract}
Resumo: Em relação ao processo morte-morrer, cada sociedade tem sua própria cultura, hábitos, crenças e valores, que aproxima ou a diferencia de outras, oferecendo aos indivíduos uma orientação de como devem se comportar e o que devem ou não fazer diante deste fato. Os profissionais de saúde são os que mais lutam contra a morte, mas sua formação e sua carreira são marcadas pelo afastamento dela. Esta pesquisa teve como objetivos: reconhecer se os acadêmicos do último período do curso de Medicina da Universidade Severino Sombra se sentem preparados para o enfrentamento do processo morte-morrer em sua prática formativa e conhecer como estes percebem que a graduação os preparou para este enfrentamento. É um estudo de natureza qualitativa, realizado através de 20 entrevistas semi-estruturadas com acadêmicos de Medicina do $12^{\circ}$ período. Os resultados apontam que, apesar da maioria dos acadêmicos se julgarem preparados para lidar com o processo morte-morrer, não foi observada, durante a graduação em Medicina, fundamentação teórico-prática adequada para este preparo. Concluímos que o preparo para o enfrentamento do processo morte-morrer dos acadêmicos de Medicina não ocorreu de forma adequada e o que ocorre não é o enfrentamento, mas sim a fuga através da criação de uma armadura protetora em que o acadêmico sente a necessidade de se transformar em uma pessoa fria, com poucos sentimentos.
\end{abstract}

Palavras chave: Morte-morrer. Acadêmicos. Medicina 


\title{
The Confrontation of the Medicine Students of University Severino Sombra fjaced with the process Death-Die
}

\begin{abstract}
In relation to the death-die process, each society has its own culture, habits, faiths and values, approaching or apart from others and offers an orientation on how individuals should behave and what they should or should not do about this fact. Health professionals are the ones who are fighting against death, but his training and his career is marked by her departure. This research aimed to: recognize that the last period of the academic progress of Medicine, University Severino Sombra feel prepared to face the death-die process in its formative practice and know how they perceive that the graduate prepared for this confrontation. It is a qualitative study, conducted over 20 semi-structured interviews with medical students of the 12th period. The results indicate that, although most students consider themselves prepared to deal with the death-die process, was not observed during undergraduate medical, theoretical-practical suitable for this preparation. We conclude that the preparation for facing the death-dying process of academic medicine did not occur properly and what happens is not coping, but the trail by creating a protective armor in which the students feels the need to transform on a cold person, with few feelings.
\end{abstract}

Keywords: Death-die. Students. Medicine.

\section{Introdução}

A ausência da reflexão sobre a morte, ou, até mesmo, o não falar sobre ela, representa o não pensar na perda dos que ficam e também na dor da solidão. No entanto, ao utilizar esse mecanismo de defesa, pode-se criar uma armadura protetora, que se manifesta pela insensibilidade e frieza, prejudicando, assim, o desenvolvimento do profissional, impedindo-o de crescer humana e profissionalmente (Takahashi, 2008. p.133).

O enfrentamento do processo morte-morrer é difícil e angustiante para quem o vivencia, podendo ser mais ainda para quem o observa, porque a morte provoca rupturas profundas entre quem morreu e o outro que continua vivendo. Isso requer ajustamentos no modo de entender, de perceber e de viver o mundo (Carvalho et al, 2006. p.551).

Da mesma forma, é verdadeiro que a morte e o morrer são temas frequentemente discutidos pelos profissionais de saude. Contudo, também é fato que muitas destas discussões estão perpassadas por questões relacionadas a como realizar procedimentos corretos, técnicas assépticas, administrar medicamentos adequados e o motivo pelo qual as terapêuticas fracassam diante da morte. Poucos são os espaços que questionam os sentimentos e as percepções desses profissionais diante da morte.

Em geral, o ensino médico se preocupa atualmente com os diagnósticos e com os tratamentos corretos, a medicina baseada em evidência. $\mathrm{O}$ acadêmico aprende que sua 
função é tratar e curar. O que importa é vencer a morte a qualquer custo e, caso isto não ocorra, surge o sentimento que muitas vezes é arrebatador para o jovem profissional: o fracasso. Frente a isso, em seu cotidiano de práticas curriculares, quando ele necessita lidar com a morte, em geral, sente-se despreparado e tende a se afastar do enfermo.

Os profissionais de saude são os que mais lutam contra a morte, mas sua formação e carreira são marcadas pelo afastamento dela. A morte não faz parte do programa de estudos nas universidades e quando ocorre, em geral, seu ensino é superficial.

Nesse contexto, o que se pode dizer sobre o futuro profissional médico cuja formação focaliza o controle e erradicação da doença? Essa questão torna-se tão pertinente ao considerarmos que a morte pode equacionar-se como um fracasso e, assim, refletir a inadequação e limitações do profissional médico. Além do sentimento de impotência na realização de suas atividades, a perda de um paciente pode levar o acadêmico de Medicina a tomar ciência de sua finitude e, muitas vezes, ser alvo da revolta dos familiares que perderam o ente querido.

Por tudo o que foi colocado, surge então a preocupação de como os acadêmicos do curso de medicina lidam ou pretendem lidar com sentimentos tão intensos e como percebem que estão sendo preparados e aprendendo a conviver com o processo morte-morrer dentro da formação médica.

No mundo atual de tecnologias, encontram-se profissionais desprovidos de qualquer avanço para enfrentar a morte como algo que esta por vir, posto que sua visão de morte, em ambiente hospitalar, vem acompanhada da idéia de fracasso do corpo, falência dos órgãos, do sistema de saúde, da sociedade, das relações com o homem e com Deus, etc. (Pitta, 1994. p.25).

É de extrema importância não tornarmos o tema morte um tabu durante a graduação e analisarmos como os acadêmicos de Medicina se sentem frente ao processo morte-morrer para que possamos trilhar caminhos que os deixem mais preparados e seguros para este enfrentamento.

Assim, o presente estudo tem por objetivo reconhecer se o acadêmico do último período do curso de Medicina se sente preparado para o enfrentamento do processo morte-morrer em sua prática formativa e conhecer como tais acadêmicos percebem que a graduação os prepara para o enfrentamento do processo morte-morrer.

\section{Referencial Teórico}

A morte é considerada como parte constituida da existência humana. É sem dúvida, um dos poucos fatos de cujo acontecimento se tem certeza. E sua imprevisibilidade, obriga o ser humano a conviver com a presença in memoriam desde o início da vida ao estágio final de seu desenvolvimento. Ao nascer, o indivíduo está em constante estado de preparação: crescendo, para assim, então, multiplicar-se e morrer. Porém, o último citado, é obscuro, a ponto de ser negado durante toda a sua existência. Fato que aponta para o seu enfrentamento ineficaz (Carvalho et al, 2006). 
No entanto, devemos aprender a conviver com as emoções que a morte nos faz sentir, respeitando o momento de transição entre vida e morte do indivíduo que está morrendo, fazendo com que este possa ter sua integralidade mantida até seu último fôlego de vida. A questão do profissional não conhecer quando e nem de que maneira virá a morte, faz encontrar os profissionais e as equipes despreparadas, pois, preparar sua própria finitude nem sempre faz parte dos planos do ser humano e de seu cotidiano.

Levando em consideração a citação da autora acima, nos perguntamos quais os princípios de valores, conceituais e, até, religiosos que buscamos para recorrer e driblar, como profissionais da área de saúde, um dos fenômenos mais comuns de nossa civilização que é a morte.

Os profissionais da saúde que atuam em meio a este "palco", onde a morte se faz presente, devem saber e estar preparados para lidar com o processo morte-morrer, onde fatores psicológicos próprios se defrontam com questões muitas vezes sem resposta.

Nas sociedades primitivas, a morte era domada, pois se pensava que o moribundo tinha conhecimento prévio de seu fim.Ninguém morria sem ser advertido previamente por outrem, ou mesmo por sua consciência através dos signos naturais e por convicção íntima, a não ser por morte súbita ou pela por, o que era considerado um castigo, já que o indivíduo não teve a oportunidade de tomar as últimas providências (Carvalho et al. 2006).

Tais signos precursores da morte trazem o moribundo à razão, concedendo-lhe tempo de ser perdoado por aqueles com quem conviveu, por Deus, através do sacerdote que lhe dava a extrema unção. Todo este processo era assistido pela coletividade e a morte apesar de individual, tornava-se pública e familiar (Carvalho et al. 2006).

Os rituais mortuários eram, até o século XIII, simplesmente aceitos de modo cerimonial, sem dramaticidade ou gestos de emoção excessivos. Com a intervenção da Igreja, passam a ser clericalizados e começam a expressar um sentido dramático que persiste na atualidade. A partir de então, cabe ao padre o papel principal, em detrimento do morto, pois o último não pertence mais nem aos seus pares ou companheiros nem à família, e sim à Igreja, fato que culmina com a mudança de atitude do ser humano diante da morte. A morte antes aceita como uma lei da natureza, que não se cogitava evitar e nem exaltar e sim aceitar, apenas com a solenidade necessária para marcar uma etapa que cada vida devia transpor (Ariès, 1981).

Atualmente, mais dramática e romântica, a morte do outro inspira saudade e lembrança, evocando nos séculos XIX e XX, um novo culto aos cemitérios. Apesar da familiaridade com a morte, a proximidade com os mortos não era algo desejado, as tumbas mantinhamnos à distância, de modo a impedir que voltassem para perturbar os vivos. Os cemitérios eram situados fora das cidades e aos cuidados da Igreja, causando assim uma ruptura entre mortos e vivos, individualizando o processo morte-morrer (Maranhão, 1999).

A complacência romântica acrescenta mais ênfase às palavras e aos gestos do moribundo, porém a mudança maior foi na atitude da assistência, que passou a ser somente após a constatação da morte e se traduzia por uma indumentária, por hábitos e pelo cuidado de seus familiares ou amigos em garantir apropriada aparência ao morto, à época velado em casa, e acompanhá-lo até o seu sepultamento (Ariès, 2003). 
De acordo com Carvalho e colaboradores, 2006, apenas a partir do século XX é que o lugar de morrer deslocou-se da casa para o hospital e a concepção moderna de morte no âmbito hospitalar reduziu-se ao mínimo, ao cuidado com o doente, que está morrendo, privando-o de informações sobre o seu estado de saúde e afastando-o da convivência com familiares e amigos.

Segundo Kluber-Ross, 2000, o morrer ficou triste demais, porque se morre na solidão. Aos sobreviventes é negado expressar a sua dor, pois a expressão de sentimentos arrebatadores consequentes à perda inspira repugnância, só se tem direito é ao luto solitário e envergonhado.

O mundo ocidental transformou a morte em tabu. Ela costuma ser escondida das crianças e banida das conversas do dia-a-dia, simplesmente pelo fato de que os sentimentos que a morte faz aflorar são intensos., Seu nome não deve nem mesmo ser pronunciado. Por si só ele já causa medo, fuga e espanto (Bernieri \& Hider, 2006).

Carvalho e colaboradores, 2006, relatam que à morte moderna, institucionalizada e medicalizada, como ocorre no cotidiano hospitalar, se aplicam inúmeras operações destinadas a fazer desaparecer o corpo e dissipar rapidamente o acontecimento mortemorrer.

Diante deste contexto, podemos afirmar que a morte é o destino certo de todos os seres vivos. No entanto, só os seres humanos podem ter consciência da própria morte, mas poucos falam dela, a maioria procura fugir do assunto.

Os profissionais priorizam suas técnicas e manobras usando artifícios tecnológicos, prolongando a vida por esses meios, deixando para segundo plano e, até, nem lembrando que naquele corpo existe um ser, que possui sentimentos, família e um sobrenome, que muitas vezes é substituído por um simples número de leito.

\section{Metodologia}

O presente trabalho se configura como um estudo de caso de natureza qualitativa considerando o fenômeno a ser estudado. Quanto à escolha da pesquisa qualitativa, justificase por tratar de um estudo no campo da compreensão humana, mais especificamente no campo da vivência educacional. Acreditamos que este tipo de abordagem nos permite acessar representações e desvelar valores que permeiam as práticas profissionais dos futuros médicos.

Foram sujeitos deste estudo, 20 acadêmicos do último período do curso de Medicina da Universidade Severino Sombra. Assim sendo, partimos da hipótese de que estes futuros profissionais médicos vão se deparar com o processo morte-morrer durante sua vida.

Inicialmente, estes foram convidados, individualmente a participar do estudo tendo sido solicitado autorização dos mesmos por meio do Termo de Consentimento Livre e Esclarecido explicando que seria feito a gravação de sua entrevista e que apesar disto, estaria garantido o seu anonimato respeitando a resolução 196/96 Ética em Pesquisa. Os entrevistados foram numerados para preservar a sua identidade. 
Os dados foram coletados por meio de entrevista semi-estruturada com o intuito de favorecer a livre expressão dos sujeitos. Antes de iniciar a entrevista, foi apresentado, aos entrevistados, o estudo e seus objetivos, individualmente e, em seguida, o roteiro de entrevista semi-estruturada, para que esses fizessem a opção em assinar ou não o termo de consentimento livre esclarecido, conforme exigência do Comitê de Ética e Pesquisa da Universidade Severino Sombra. Após assinatura do Termo de Consentimento Livre e Esclarecido, deu-se inicio às entrevistas e assim, sucessivamente, repetindo o procedimento com todos os outros entrevistados, de acordo com o período de disponibilidade dos mesmos, respeitando dia e hora.

As entrevistas foram gravadas e foi permitida a fala sem restrições, quanto ao tema exposto, o que trouxe à tona conteudo suficiente para análise. O conteudo das entrevistas foi transcrito na íntegra, para facilitar a visualização das respostas e captar a essência dos conteúdos. As repostas foram analisadas segundo a técnica da análise de conteúdo, na modalidade análise temática.

\section{Resultados}

Inicialmente, foi feita uma pré-análise do material com repetidas leituras, através de profunda reflexão, até atingir uma impregnação desse conteúdo. Em um segundo momento, foi feita a exploração deste material, com a categorização de núcleos comuns, que demonstraram a realidade dos acadêmicos sobre a temática.

Os dados foram recortados, e compilados, de acordo com as questões norteadoras usadas na entrevista, a partir das unidades de significado, sendo agrupados os de significação aproximada. Foram utilizados os escritos de Laville \& Dionne, 1999, para elaborar a análise após o tratamento inicial dispensado. A opção por esse procedimento foi pela facilidade em se trabalhar com os dados da coleta. Segundo as autoras citadas, o recurso de utilização de uma grade aberta é frequente nos estudos de caráter exploratório, quando o pesquisador conhece pouco a área de estudo e sente necessidade de conhecimento de uma situação, ou de um fenômeno, a fim de anunciar hipóteses.

O material produzido individualmente nas entrevistas, além de ter passado pelo mesmo processo, está apresentado na forma de crônicas.

Os dados foram estruturados em categorias na tentativa de buscar contornos do sistema de significação que, no seu conjunto revelassem as representações coletivas do processo morte-morrer.

\section{Discussão}

Partimos da sistematização de duas categorias que representam o eixo em torno do qual o produto da dinâmica realizada se articula. Neste texto, será apresentada a análise dos dados obtidos nas duas categorias definidas, ou seja, aquela relacionada ao "sentir-se preparado frente ao processo morte-morrer" e a relacionada à "contribuição do curso de graduação em Medicina, no preparo para o enfrentamento do processo morte-morrer". 


\section{Categoria 1 - Sentir-se preparado frente ao processo morte-morrer}

Conhecer o quanto os acadêmicos de Medicina estão preparados em relação à temática do processo morte-morrer é poder contextualizar o universo de valores e atitudes em que estão inseridos. No que diz respeito à formação médica, o treinamento muitas vezes acaba afastando a emoção do acadêmico diante do paciente. Desta forma, o acadêmico passa a reconhecer a doença e não a pessoa.

Nesta categoria converge a reprodução de ação emocional acerca do processo mortemorrer. Amaioria dos acadêmicos entrevistados se sentem preparados para o enfrentamento deste processo.

"A primeira vez foi bem dificil, foi bem conflitante. Mas depois a gente vai aprendendo que faz parte." (Fragmento da entrevista 8)

"Como o paciente não é próximo da gente, a gente não tem um envolvimento tão grande, é tranquilo." (Fragmento da entrevista 3)

"Hoje em dia, como estou no décimo segundo período, já é um pouco mais natural, mas, no começo, quando perdi minha primeira paciente foi mais dificil, porque você se envolve afetivamente." (Fragmento da entrevista 7)

"Agora acredito que sim. Era um medo que eu tinha, mas depois que aconteceu e foram acontecendo outras vezes, eu vi que que não era tão...” ( Fragmento da entrevista 14)

"Me considero preparado.” (Fragmento da entrevista 19)

Alguns indivíduos comungam da dificuldade em enfrentar esse processo, compartilham de um sentimento comum de dor e tristeza pela perda, sentimento de ambivalência, que permeia o aspecto profissional sem deixar de lado o aspecto humano de interação com essa realidade.

"Não, não me sinto preparado, porque somos seres humanos e somos médicos. Somos mais frios do que o normal, mas dizer que estou preparado... Não. Ainda terei pacientes exclusivamente meus, que vou perder e não saberei nunca lidar com isso." (Fragmento da entrevista 11)

"Acho que cada caso é um caso. Acho a gente nunca está 100\% preparado." (Fragmento da entrevista 8)

A experiência da morte é vivenciada pelos acadêmicos de medicina, que se defrontam cotidianamente com a doença, com a dor e com a morte. Todo esse conjunto de experiências diárias pode tornar latentes, para os acadêmicos, seus sentimentos de impotência diante do não solucionável.

"Bom... Fico sempre triste, sempre acho que poderia ter feito algo a mais. Mesmo fazendo tudo o que está ao nosso alcance, sempre acho que podíamos ter feito melhor." (Fragmento da entrevista 1) 
Para Novaes e Trindade (2007), o contato do estudante de medicina com a morte não pode ser reduzido somente à dissecção de cadáveres em atividades de anatomia. Os autores alertam que esse momento, quase como um rito de passagem em escolas tradicionais, marca sobremaneira a futura postura do estudante, que parece aprender e adotar uma postura de maior distanciamento com a condição humana, já que o foco é unicamente a aprendizagem da anatomia humana.

"Não, não me sinto preparado, porque somos seres humanos e somos médicos. Somos mais frios do que o normal, mas dizer que estou preparado.. Não. Ainda terei pacientes exclusivamente meus que vou perder e não saberei nunca lidar com isso". (Fragmento da entrevista 11)

\section{Categoria 2 - Contribuição do curso de graduação em medicina no preparo para o enfrentamento do processo morte-morrer}

Alguns autores afirmam que, se a morte é parte do ciclo da vida humana, então, cuidar do corpo que está morrendo deve ser parte integral dos objetivos da Medicina, assim como acreditam que a exclusão dos temas da morte e do morrer, dentro da formação médica, é intencional e está relacionada com o fato de os médicos não se envolverem com o que acontece com os pacientes (Azeredo, 2011).

Porém, fica claro nas falas dos alunos entrevistados, a pouca contribuição das disciplinas da graduação em Medicina no preparo dos acadêmicos para o enfrentamento do processo morte-morrer.

"Poucas vezes, me lembro, durante a disciplina de ética médica e durante a disciplina de medicina intensiva, que falam um pouco de ética, de morte. Foi trabalhado somente essas duas vezes. (sic) Foram feitas discussões de casos clínicos, discussões de condutas, sobre distanásia. Mas não muitas vezes, só nessas duas ocasiões”. (Fragmento da entrevista 11)

"Não. Nenhuma vez, nenhuma vez. Não me lembro de ter sido trabalhado isso, pode ter sido citado, esporadicamente, mas trabalhado não. Nenhuma bibliografia, nada." (Fragmento da entrevista 14)

A perda da humanização e da integralidade deixa transparecer a dicotomia entre saúde e doença, entre prevenção e assistência. A dor, a aflição, o sofrimento e a morte não se incluem na detecção das patologias e em sua prevenção, exceto pelo olhar biológico do corpo humano. A humanização e a integralidade parecem seguir fora do eixo estrutural da formação médica. Discutir temas como medo, sofrimento e morte parece não ser um foco central na formação dos profissionais de saúde. A abordagem parece ser sempre superficial.

“Em momento nenhum. Foipouco falado na Geriatria, mas bem pouco...” (Fragmento da entrevista 10) 
"Apenas na disciplina de geriatria e gerontologia, superficialmente." (Fragmento da entrevista 2)

"Eu acho que na cadeira de psicologia, mas não lembro como." (Fragmento da entrevista 5)

É preciso ficar alerta para aquilo que os próprios entrevistados julgam ser o "momento" mais adequado para trabalhar academicamente o tema da morte. Segundo eles não se trata de inserir mais uma disciplina teórica sobre o assunto:

"Ainda está muito fraco. Falar na sala de aula é muito tranquilo, mas a parte prática, você pegar e fazer... Isso é muito delicado. (Fragmento da entrevista 9)

"Eu acho que faz falta na faculdade essa abordagem. Eu acredito que foi um processo, por isso consegui encarar isso com naturalidade, consegui trabalhar isso ao longo da faculdade, mas de forma particular, não tendo o suporte da faculdade. Só que eu acho que isso é uma falha da faculdade não ter essa abordagem. Eu nunca tive uma abordagem nesse sentido, zero." (Fragmento da entrevista 14)

Muitos cursos de formação de profissionais da saúde estão carentes, em seus currículos, de disciplinas que abordem a morte, o luto e o processo de morrer. A morte no sentido da sua inexorabilidade, não como uma inimiga a vencer, mas como uma etapa da vida que necessita ser cuidada.

"É muito deficiente. Eu acho que aqui não temos uma preparação adequada para lidar com estas situações. É uma coisa que, infelizmente, você terá que aprender com sua vivencia, quem tem boa base como na família, livros e religião, é mais fácil. Quem não tem é bem mais dificil." (sic) (Fragmento da entrevista 3)

“A gente aqui não é preparado pra isso, então a gente acaba assumindo uma posição de acadêmico e sem estar preparado pra um dia assumir essa posição de médico... que no caso a gente vai assumir daqui a pouco tempo, então a gente só acompanha o médico..." (Fragmento da entrevista 9)

\section{Conclusão}

De acordo com as entrevistas realizadas e as leituras dos textos aqui citados, é possível concluir que o acadêmico de medicina, em sua formação, aprende a se comprometer com a vida em detrimento da morte, como se essa não fizesse parte daquela. Afinal, toda a sua capacitação é para a cura, que traz gratificação do aprendizado e recompensa do esforço realizado.

Quando a morte se apresenta, ela traz para o acadêmico a sensação de frustração e um sentimento de incapacidade, pois existe um despreparo técnico, segundo as falas dos próprios acadêmicos, em lidar dignamente com a morte, já que a cura parece ser a grande meta da Medicina. Contudo os acadêmicos sabem que não se pode negar a existência da morte e nem o fato de que ela vai estar no seu dia-a-dia. Sendo assim, a preparação para 
enfrentá-la é a melhor alternativa. Muitas vezes, o que ocorre, não é o enfrentamento, mas sim a fuga através da criação de uma armadura protetora, em que o acadêmico sente a necessidade de se transformar em uma pessoa fria, com poucos sentimentos. Isto converge para a real necessidade, que é a de justamente, se aproximar do paciente e dos familiares nesse momento difícil, mas para isto é necessário um preparo. Esse preparo não ocorreu de forma adequada durante o período da graduação, conforme as falas dos acadêmicos.

Esta pesquisa mantém a discussão sobre a importância da necessidade de um preparo teórico-prático sobre o enfrentamento do processo morte-morrer durante a graduação em Medicina.

Deste modo, o estudo não se esgota, mas limita, para o momento, os apontamentos apresentados, considerando que esses podem aproximar-se de forma oportuna da realidade a qual foi apontada neste momento, em que passamos por grandes e reais transformações no contexto social e na profissão médica, deixando-nos não orientações ou conhecimentos fechados, mas o despertar de reflexões iniciais que poderão, assim, como o processo que estamos vivendo, transformar-se em grandes debates rumo a grandes conquistas. 


\section{Referências}

Ariès, Philippe (2003). História da morte no ocidente: da idade média aos nossos dias. Rio de Janeiro: Ediouro.

Áriés, Philippe (1981). O homem diante da morte. Rio de janeiro: Francisco Alves.

Barbus, A.J. (1975). The dying person's Bill of rights. American Journal of Nursing Company, v.75, n.99, p.38.

Bernieri, Jamine \& Hirdes, Alice (2006). O preparo dos acadêmicos de enfermagem brasileiros para vivenciarem o processo morte-morrer. Texto contexto - Enferm. Florianópolis, v.16, n.1.

Boff, L. (2002). Saber Cuidar: ética do humano: compaixão pela terra. $8^{a}$ Ed. São Paulo: Vozes.

Brandão, Z. (2002). Pesquisa em Educação : conversar com pós graduandos. Rio de Janeiro : Ed PUC-RIO; São Paulo: Loyola.

Brêtas, JRS; Oliveira, JR \& Yamaguti, L. (2004). Reflexões de estudante de enfermagem sobre morte-morrer. Revista de Enfermagem da USP. 40(4): 477-83.

Carvalho, LS; Oliveira, MAS; Portela, SC et al. (2006). A morte e o morrer no cotidiano de estudantes de Enfermagem. Rev. Enferm. UERJ. v.14, p.551-557.

Conselho Federal de Enfermagem. (1993). Código de ética dos profissionais de enfermagem. Rio de Janeiro.

Horta M P. (1999). Eutanásia: Problemas éticos da morte e do morrer. Bioética. 7 (1): 59-64.

Kübler-Ross, E. (1998). Sobre a Morte e o Morrer. 8.ed. São Paulo: Martins Fontes.

Laville, C \& Dionne, J. (1999). A construção do saber - Manual de metodologia da pesquisa em ciências humanas. Belo Horizonte: Editora UFMG. OS CAMINHOS DA CIÊNCIA

ludke, M; André, M. (1988). Pesquisa em educação: abordagens qualitativas São Paulo: EPU. 99 p.

Maranhão J L S. (1999). O que é morte. $4^{\circ}$ ed. São Paulo: Brasiliense.

Minaio MCS. (2000). O desafio do conhecimento - pesquisa qualitativa em saúde. São Paulo(SP) HUCITE.

Novaes MRCG \& Trindade EM. (2007). A morte e o morrer: considerações bioéticas sobre a eutanásia e a finitude da vida no contexto da relação médico-paciente. Com. Ciências Saúde. 18(1): p.69-77.

Penna, CMM; Nova, LSV; Barbosa, SA. (1999). A morte e seus significados: um estudo compreensivo com professores e alunos de enfermagem. Revista de Enfermagem, Belo Horizonte, v.5,n.9 e 10, p. 20-38.

Pitta, A. (1994). Hospital: Dor e morte como oficio. $3^{\text {a }}$ ed. São Paulo: HUCITEC.

Rodrigues, CJ. (2006). Tabu da morte. Antropologia e saúde. Editora Fiocruz. $2^{\mathrm{a}}$ edição. 
Silva, J. (2007). Preparo e percepções da equipe de enfermagem no processo de morte e morrer. Revista Hórus - Volume 4, número 1, p. 232-245.

Silva, KS; Ribeiro, RG; Kruse MHL. (2009). Discursos de enfermeiras sobre morte e morrer: vontade ou verdade? Rev. bras. enferm. vol.62, no.3,p.451-456. Brasília Mai/ Jun. 